\title{
Endocrine disrupter verdict left open
}

[WASHINGTON] Insufficient data exist to provide an accurate assessment of the risks to public health posed by the chemicals known as endocrine disrupters in the low ambient doses found in the environment, according to the US National Research Council (NRC).

A panel of experts put together by the council, part of the National Academies complex, has agreed that some of the chemicals can be shown to adversely affect reproduction and development of wildlife at high doses.

But, after a drawn out and highly-charged four-year investigation, the members of the panel disagreed about the extent to which the concentrations of the chemicals found in the environment constitute a public health risk.

The release of the study - which leaves the endocrine disrupter question unresolved - was broadly welcomed by both sides in the debate, each being left free to interpret the outcome as they saw fit.

Theo Colburn of the Worldwide Fund for Nature (WWF) argues that "this is a clear message that there's enough evidence that we should be taking precautions, and acting to fill gaps in our knowledge". Colburn's book, Our Stolen Future, expounded the endocrine disrupter hypothesis.

But the Chemical Manufacturers Association said the study "found little evidence to support certain allegations about chemicals and adverse effects in people". It said the report was "a thorough work that provides solid direction for continued research".

Proponents of the endocrine disrupter hypothesis, such as the WWF, argue that some chemicals mimic oestrogens and other sex hormones in ways that can have extremely adverse effects, even in doses far too small to trigger a conventional toxic response.

Some proponents attribute many types of cancer, as well as an alleged global decline in human sperm counts, to the effect. Because of disagreements on the NRC panel about the validity of the hypothesis, it chose to call the chemicals 'hormonally-active agents'.

The panel recommends more research to test the endocrine disrupter hypothesis, including long-term studies of exposed populations. But it concedes that even this may fail to bridge the bitter divisions between adherents to the hypothesis and sceptics. "Some of the differences reflect areas where additional research would help, others reflect differing judgements about the significance of the existing information," says the summary of the report, released on 3 August.

Ernst Knobil, an endocrinologist at the University of Texas at Houston and chair of the panel, warns that these differences are likely to persist. Controls will be difficult to find for long-term human studies because the chemicals are so pervasive in the environment, he says. And the banning of production of some

NATURE |VOL 400 | 12 AUGUST 1999|www.nature.com

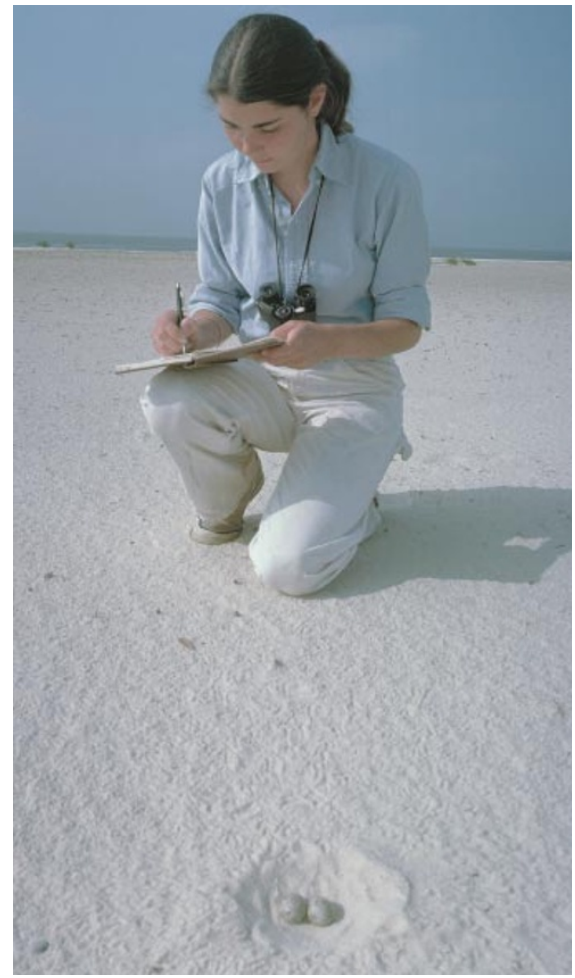

At risk? Eggs of the least tern — an endangered species and possible victim of PCBs - being checked in Gulfport, Mississippi.

of the most active chemicals, such as polychlorinated biphenyls (PCBs), will gradually reduce their concentration in the environment, making their effects even more elusive.

Policy-makers say that the report could lend impetus to research programmes. The report "may help to get the research programme back on track," says a White House

aide who follows the issue. The Clinton administration has proposed that the Environmental Protection Agency should spend $\$ 21$ million on research into the subject next year, up from $\$ 16$ million this year. A House of Representatives appropriations subcommittee has proposed adding a further $\$ 5$ million.

But the report is less than enthusiastic about the quality of existing research. "In much of the literature, distinctions between environmental concentration, exposure and dose are often not made," it says. "This failure can reduce the relevance and value of research results."

The panel agreed that "many wildlife studies show associations between reproductive and developmental anomalies and exposure to environmental contaminants, some of which are hormonally-active agents". It also said that there is evidence that prenatal exposure to high concentrations of some of the chemicals "can affect the developing nervous system".

It found that the literature did not support associations between adult exposure to the chemicals and breast cancer or other hormonally sensitive cancers. But it noted that few studies had checked concentrations of these chemicals in the body against cancer risk in adults; none had checked for the effect of exposure to hormonally-active agents during fetal life on cancer incidence later on.

The study also found that, because of wide and unexplained geographical variations, the current data do not support (or refute) the widely-propagated theory that overall human sperm counts have been falling.

ColinMacilwain

\section{Brain drain accelerates from Siberia}

[Moscow] The exodus of trained scientists from the Siberian branch of the Russian Academy of Sciences is accelerating. A new report claims that last year the academy lost 668 scientists, including 384 with doctorates; these figures are up from 535 and 288 in 1997.

The report, prepared by the local Centre for Social Adaptation and the Philosophy and Law Institute of the Siberian branch of the academy, points out that only five to ten per cent of those scientists who left the academy went abroad, but that those who did are among the best in their fields.

The survey lists several reasons for the exodus. The first, named by almost 95 per cent of respondents, is the higher salaries that scientists receive abroad. The second, given by 80 per cent, is the declining prestige of science in Russia.

The third reason for leaving is a desire to get closer to new ideas, conferences and other scientific events. The final reason, identified by one third of respondents, is a fear for the future of children in Russia.

According to the report, Russia has paid a high cost for the emigration of its scientists, who were expensive to train. But it points out that those who leave Russia but stay in science are not lost completely as they often maintain links with former colleagues. Most say they would like to return when the situation in Russian science improves.

More damaging is the fact that many talented scientists move into business and other work unrelated to science.

The final loss to Russian science, says the report, is the low productivity of scientists experiencing harsh living conditions and low morale. One in four scientists at the Siberian branch of the academy live below the official poverty line, and over 40 per cent have a below-average standard of living. Carl Levitin 